\title{
1 Title. Low stomatal sensitivity to vapor pressure deficit in 2 irrigated common, lima and tepary beans
}

3 Author names and affiliation. Viviana Medina ${ }^{1}$, Jorge C. Berny-Mier y Teran ${ }^{1}$, Paul Gepts,

4 Matthew E. Gilbert*

5 Department of Plant Sciences, Mail Stop One, University of California Davis, One Shields Ave,

6 Davis 95616 CA, USA

$7 \quad{ }^{1}$ both authors contributed equally to this paper

$8 \quad *$ Corresponding author. megilbert@ucdavis.edu Tel.: 530-752-7846

9 E-mail addresses: vmedina@ucdavis.edu, jcberny@ucdavis.edu, plgepts@ucdavis.edu, 10 megilbert@ucdavis.edu

11

12 
13 ABSTRACT

14 A limited transpiration rate under high vapor pressure deficit (VPD) could be used to conserve 15 soil water for later use under drought conditions. Many crops show this behavior either as limited 16 transpiration or decreases in stomatal conductance. However, little work has been done in 17 Phaseolus. Four experiments evaluated stomatal closure across a range of VPD for well-watered 18 plants, each experiment using varying combinations of genotypes of common (15), lima (6) and 19 tepary beans (7 genotypes). A two-year experiment found genotypic variation in average 20 stomatal conductance, but genotypes only had 14\% stomatal closure between a VPD of 1 to 4 $21 \mathrm{kPa}$. In comparison, soybean, which is known to close stomata, had a $40 \%$ decrease for similar 22 conditions in Davis, CA, USA. In a second field experiment and outdoor pot experiments, 23 genotypes from the three species displayed, on average, a 34,50 to $45 \%$ increase in stomatal 24 conductance with increasing VPD. Six genotypes were statistically indistinguishable from a $40 \%$ 25 decrease, but all had low probability $(p<0.21)$ of having $40 \%$ closure, and some showed little 26 closure in other experiments. The VPD range measured in this study was large relative to the 27 range for hot, arid California, thus the results are generalizable: most Phaseolus beans are not 28 expected to have appreciable stomatal closure under well-watered conditions. Thus, there is 29 limited evidence that Phaseolus has somegenetic diversity in stomatal responses to VPD, 30 relative to that shown in other species. However, there was constitutive genetic variation in 31 species and genotypic stomatal conductance under low VPD conditions. 
33 Keywords: soil water deficit avoidance, drought, P. vulgaris, P. lunatus, P. acutifolius, limited transpiration

Abbreviations: $\mathrm{C}$, common bean; $g_{\mathrm{H} 2 \mathrm{O}}$, stomatal conductance to water vapor; L, lima bean; $\mathrm{P}$, cowpea; $T$, tepary bean; $T_{\text {air }}$, air temperature; VPD, vapor pressure deficit.

\section{Introduction}

A limited transpiration rate at high vapor pressure deficit (VPD) for well-watered conditions has been used as a mechanism to breed water conservative crops (Sinclair et al., 2010;

42 Sinclair et al., 2016). Using the technique of weighing pots under high VPD, many crops have

43 been found to have this behavior, including legumes such as: chickpea (Zaman-Allah et al., 44 2011), cowpea (Belko et al., 2012), peanut (Devi et al., 2010), and soybean (Sadok and Sinclair, 45 2009), and other crops like corn (Yang et al., 2012; Gholipoor et al., 2013), sorghum (Gholipoor et al., 2010), tall fescue (Sermons et al., 2012), and wheat (Schoppach and Sadok, 2012). An

47 alternative technique can be used for field evaluations, where measurements of stomatal closure 48 under high VPD would correspond to limited transpiration, and has been applied, for example, to 49 soybean (Gilbert et al., 2011; Medina and Gilbert, 2016) and peanut (Shekoofa et al., 2015).

50 However, little work has determined whether this behavior is found in common bean (Phaseolus

51 vulgaris L.) or other domesticated Phaseolus species. One greenhouse study did find that

52 varieties of common bean had stomatal closure when exposed to the VPDs at the extreme of

53 those experienced during growth (Comstock and Ehleringer, 1993). 
Finding such stomatal closure in beans in the field would be useful, as stomatal closure

55 early in the season would lead to a decrease in water use, and thus soil water conservation for

56 later periods of drought, as evidenced by delayed wilting in soybean (King et al., 2009).

57 Common bean may benefit from conservative water use as they are often grown in drought prone environments(Singh, 2001; Polania et al., 2016). Despite a large quantity of drought related work

59 on P. vulgaris, and a dry origin for many genotypes (e.g. Northwestern Mexico and Chile), limited transpiration or stomatal closure behavior remains obscure in this species.

Less drought research has been done on lima bean (P. lunatus L.), despite the wide

62 adaptation range of this species (Debouck, 1999; Maquet et al., 1999; Gepts, 2001; Freytag and

63 Debouck, 2002; Delgado Salinas and Gama López, 2015). Tepary bean (P. acutifolius A. Gray)

64 is the "archetypal" drought tolerant crop - growing in the agriculture system with the least

65 annual rainfall in the world (Freeman and Station, 1912; Nabhan, 1990; Rainey and Griffiths,

66 2005). However, tepary drought tolerance may derive from a fast completion of its lifecycle,

67 thereby avoiding soil water deficit. The species may also rely on just one monsoonal rainfall season; this would not allow provision of future rainfall, which water conservative behavior would benefit from. Thus, including the broadly adapted lima bean and the extreme arid environment tepary would increase the chances of finding alternative stomatal behaviors.

72 variation in stomatal closure at high evaporative demand under well-watered conditions. The 73 hypothesis was that genotypes/species from arid environments would have the greatest closure 74 under high evaporative demand, conserving the most water. Similarly, the least commercially 75 improved species, tepary bean, would have more drought-adapted traits, such as water 76 conservation and lower stomatal conductance. 
78 2. Material and methods

79

Four experiments were undertaken on combinations of species and genotypes (Table 1):

81 Experiment A: a field trial on eight common bean genotypes, and some other selections in 2013

82 and 2014; Experiment B: an outdoor pot experiment in 2014 on the same eight genotypes as in

83 Experiment A; Experiment C: a parallel pot experiment to B on three genotypes from each of the

84 three bean species; Experiment D: a field trial in 2015 on four to five genotypes from each of the

85 three bean species.

86

87 Table 1. Genotypes of beans used in the pot and field experiments

\begin{tabular}{|c|c|c|c|c|c|c|c|}
\hline \multirow[t]{2}{*}{ Species } & \multirow[t]{2}{*}{ Genotype } & \multirow[t]{2}{*}{ Type/origin } & \multirow{2}{*}{$\begin{array}{l}\text { Growth } \\
\text { habit }^{\mathrm{a}}\end{array}$} & \multicolumn{4}{|c|}{ Experiment } \\
\hline & & & & $\mathrm{A}$ & $\mathrm{B}$ & $\mathrm{C}$ & $\mathrm{D}$ \\
\hline Vigna unguiculata & CB46 & CA, UCD & II & $\mathrm{Y}_{2013^{\mathrm{b}}}$ & & & \\
\hline \multirow[t]{7}{*}{ P. vulgaris } & SEA5 & $\mathrm{M}, \mathrm{CIAT}^{\mathrm{c}}$ & II & Y & $\mathrm{Y}$ & & \\
\hline & UCD9634 & $\mathrm{D} / \mathrm{J}, \mathrm{UCD}$ & II & Y & $\mathrm{Y}$ & & \\
\hline & Flor de Mayo Eugenia (FDM) & J, INIFAP & III & $\mathrm{Y}$ & $\mathrm{Y}$ & & $\mathrm{Y}$ \\
\hline & Matterhorn & D, MSU & II & $\mathrm{Y}$ & $\mathrm{Y}$ & & \\
\hline & Victor & D/J, USDA, WSU & III & Y & $\mathrm{Y}$ & & $\mathrm{Y}$ \\
\hline & Pinto San Rafael (PSR) & $\mathrm{D}, \mathrm{INIFAP}$ & III & $\mathrm{Y}$ & $\mathrm{Y}$ & & \\
\hline & L88-63 & $\mathrm{M}, \mathrm{MSU}$ & II & $\mathrm{Y}$ & Y & & \\
\hline
\end{tabular}




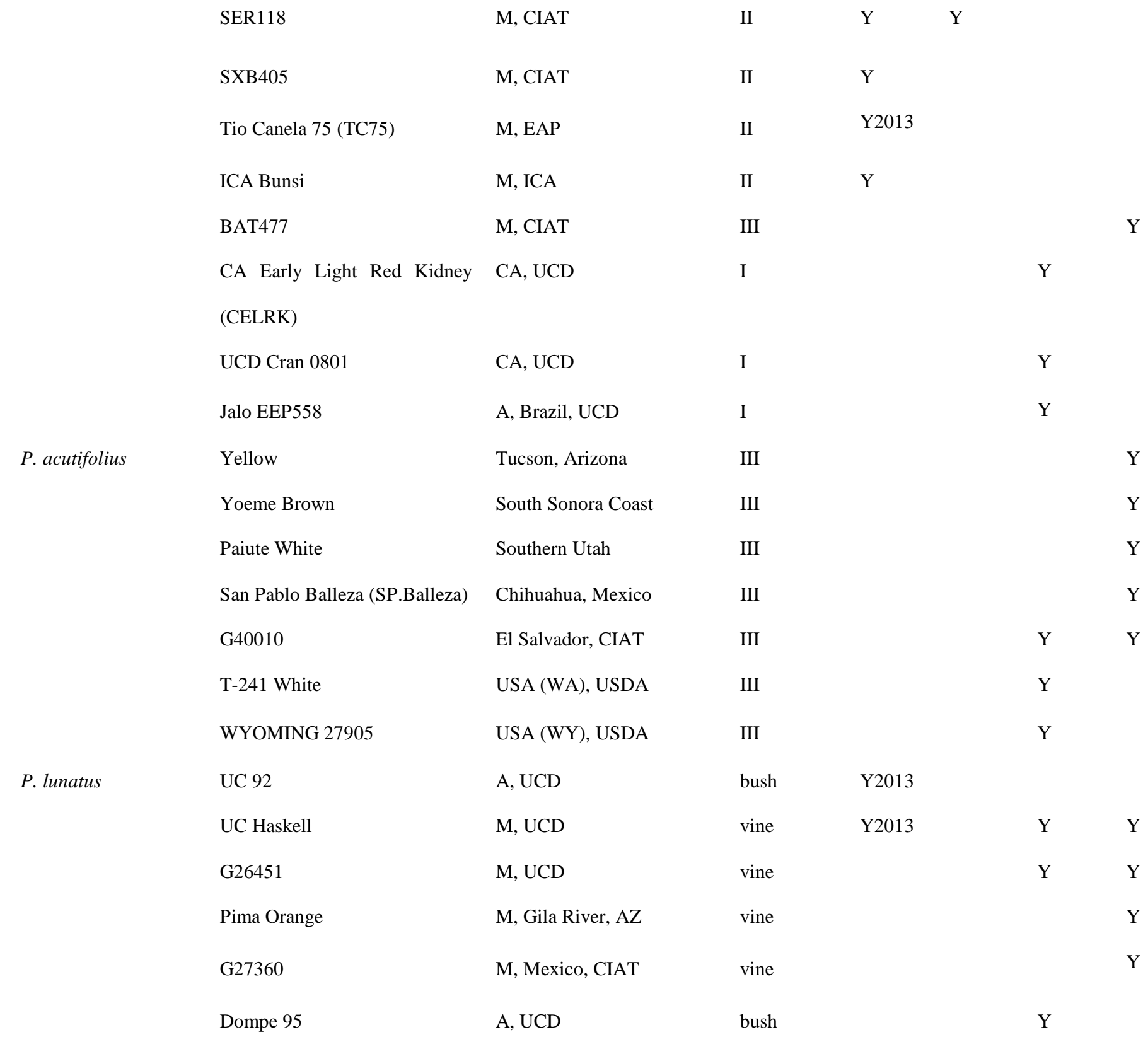

88 a Growth Habit: I, determinate bush; II, indeterminate bush; III, indeterminate prostrate; IV, 89 indeterminate climbing.

$90 \mathrm{~b}$ included in experiment in 2013 but not 2014.

91 c Abbreviations: A, Andean; CA, California; CIAT, International Center for Tropical 92 Agriculture; D, Durango; EAP, Escuela Agrícola Panamericana - Zamorano, Honduras; J, 
93 Jalisco; ICA, Instituto Colombiano de Agricultura M, mesoamerican; UCD, University of

94 California Davis; USDA, United States Department of Agriculture.

95 The selection of common bean and lima bean genotypes used for these experiments 96 included representatives of Andean and Mesoamerican centers of domestication and, for 97 common bean, included diverse eco-graphic races from Mexico (Durango and Jalisco). Tepary 98 bean accessions were selected from geographically distinct areas (Table 1), although less is 99 known about tepary diversity (Schinkel and Gepts 1988, 1989; Blair et al. 2012).

All field trials were performed during the summer on the Plant Sciences Research Station 101 of the University of California Davis (38.53N, -121.78E). This Central Valley site receives no 102 rainfall in the summer $(<0.25 \mathrm{~cm})$ due to a hot, arid Mediterranean climate (Csa, Köppen climate 103 classification). The soil type for the 2013 and 2014 field experiments was a Yolo silty loam, fine 104 silty, mixed, nonacid, thermic Mollic Xerofluvents, and in 2015 a similar adjacent Reiff very fine 105 sandy loam.

A field experiment was conducted in 2013 and 2014 on eight diverse genotypes of common bean and some other common and lima bean genotypes in some of the years (Table 1; 110 planted: 5 Jun 2013 and 8 Jun 2014, harvested: 10 Sep 2013 and 12 Sep 2014). The experiment 111 consisted of three blocks/replications of the genotypes planted in random order, a randomized 112 complete block design (RCBD) in 2013, and in 2014 a staggered design was used where initial 113 measurements were done on three well-watered blocks, subsequently the second block was 114 subject to terminal drought starting on 14 Jul 2014. Thus, the two years did not have a consistent 
115 blocking design, and block effects were not accounted for. The genotype plots consisted of one

116 single row bed, $6.1 \mathrm{~m}$ long, with $0.76 \mathrm{~m}$ spacing between rows. A small alley at the end of the

117 plot separated plots $(\sim 1 \mathrm{~m})$, otherwise all plots were either bordered by other genotypes, or a five

118 row field border planting. Plants were sampled for gas exchange more than $1 \mathrm{~m}$ into the plot. The

119 seeds were machine planted, $10 \mathrm{~cm}$ apart, flood pre-irrigated, and later maintained with four

120 flood irrigation events. Each flood irrigation brought the rooting volume to field capacity. Pest

121 and diseases were controlled using conventional chemical controls. Gas exchange measurements

122 on well-watered plants were made on all blocks in random order within five days of flood

123 irrigation. Water deficit blocks (2014) were measured on the same days as well-watered plants in

124 random order, alternating between well-watered and water deficit blocks.

\subsection{Experiment B (Outdoor pots 2014)}

Plants were grown in large pots $(11.4 \mathrm{~L})$ in an open field at the UC Davis Orchard Park

128 Greenhouse facility during the summer of 2014 in a RCBD. Four blocks were planted with 129 random order of genotypes within the blocks, and each well-watered pot had a water deficit pot 130 adjacent to it. A border, one pot wide, of a common bean genotype (BAT477) was planted 131 around the entire experiment. Eight common bean genotypes from Experiment A were measured 132 in this experiment (Table 1). Pots had a custom mix of sand, topsoil, pumice, fir bark and peat 133 moss, 3:3:2:1:1, by volume. Pots were whitewashed and the grow area covered with 50\% shade 134 cloth to prevent pot heating. Three seeds of a genotype were planted per pot along with those of 135 another genotype, BAT477. After emergence, seedlings were thinned so that there was only one 136 seedling per genotype per pot. Measurement of BAT477 acted as a within pot control for 
137 variation between pots across space and time. All plants were fertigated with a modified 138 Hoagland solution using a pressure compensating dripper. After establishment (two weeks), two 139 stakes were placed to provide anchorage and support for each plant per pot, and the overhead 140 shade removed when the developing plant canopy was considered to prevent pot overheating.

141 The experiment extended from planting (11 Aug 2014) to harvest of biomass (19 Sep 2014).

142 Manual weeding and pesticides were applied as needed. Water was withheld from water deficit 143 pots for seven days from 22 days after planting, leading to rapid dry-down in comparison to the 144 field experiments.

\subsection{Experiment $C$ (Outdoor pots 2014)}

Plants were grown in the same arrangement and at the same time as described in B, but 148 consisted of a different grouping of genotypes, in this case three genotypes of common, lima and 149 tepary beans (Table 1). Different sampling days and a separate LICOR6400 to the other 150 experiments was used to measure these genotypes (Table 2).

152 Table 2.

153 Weather summary for the days of measurement

\begin{tabular}{llll}
\hline Experiment & Date & $T_{\text {air }}$ range & Max. VPD \\
& $(\mathrm{m} / \mathrm{dd} / \mathrm{yyy})$ & $\left({ }^{\mathrm{o}} \mathrm{C}\right)$ & $(\mathrm{kPa})$ \\
\hline A (field) & $7 / 18 / 2013$ & $11.6-33.6$ & 4.1 \\
& $8 / 6 / 2013$ & $9.8-28.1$ & 2.4
\end{tabular}




\begin{tabular}{llll} 
& $8 / 16 / 2013$ & $16.5-34.4$ & 3.8 \\
& $7 / 17 / 2014$ & $16.7-28.7$ & 2.1 \\
& $7 / 31 / 2014$ & $15.9-36.2$ & 4.5 \\
B (pots) & $9 / 4 / 2014$ & $11.8-34.8$ & 5.5 \\
& $9 / 6 / 2014$ & $11.3-32.2$ & 4.6 \\
C (pots) & $9 / 7 / 2014$ & $11.5-32.4$ & 4.6 \\
B and C (pots) & $9 / 10 / 2014$ & $17.9-36.5$ & 6.2 \\
& $9 / 12 / 2014$ & $12.8-37.5$ & 6.9 \\
& $9 / 14 / 2014$ & $15.3-35.2$ & 5.4 \\
& $9 / 16 / 2014$ & $12.7-32.5$ & 4.5 \\
& $7 / 28 / 2015$ & $16.3-38.6$ & 5.8 \\
& $8 / 5 / 2015$ & $10.6-32.5$ & 3.4 \\
& $8 / 17 / 2015$ & $14.2-39.2$ & 5.8 \\
& $8 / 24 / 2015$ & $13.1-33.9$ & 4.0 \\
& $8 / 31 / 2015$ & $12.9-33.3$ & 3.8 \\
\hline
\end{tabular}

154

155

2.4. Experiment D (Field 2015)

156

A field experiment was conducted on four genotypes of common and lima bean, and five

157 of tepary bean selected based on indeterminate growth habit to control for differences among the

158 species (Table 1; planted: 6/21/2015, harvested: 10/22/2015). The experiment consisted of five

159 blocks/replications of the 13 genotypes planted in random order, a RCBD. Genotype plots

160 consisted of two $1.50 \mathrm{~m}$ wide and $3.05 \mathrm{~m}$ long double row beds, with $0.76 \mathrm{~m}$ spacing between

161 rows (i.e. a plot was four rows). The seeds were hand planted, $10 \mathrm{~cm}$ apart, sprinkler irrigated for

162 establishment, and later maintained with $20 \mathrm{~cm}$ deep, subsurface drip. Each block was split by a

163 two row border and irrigation was withheld from the second plot 30 days after planting. The 
164 experiment was surrounded by a two row border (east-west) or 3.05m long plot (north-south) of 165 varying genotypes. Gas exchange data was only collected from the two middle rows at least $1 \mathrm{~m}$ 166 from each end of the row. Pest and diseases were controlled with using conventional chemical 167 controls.

171 Management Information System (CIMIS, 2015) for the period of 1983 to 2015. The weather 172 station is within $1500 \mathrm{~m}$ of all the field and outdoor pot sites. The daily maximum air 173 temperature and minimum relative humidity was used to calculate the maximum daily VPD 174 percentiles for the months of the year. Historically, Davis CA has the majority of days in a June 175 to September growing season with maximum daily VPD between 2.4 and $4.4 \mathrm{kPa}$ (Fig. 1). At the 176 extreme, 95\% of days during the growing season have maximum daily VPD's between 1.1 and $177 \quad 6.1 \mathrm{kPa}$. These are extreme values, as the majority of daylight hours have lower VPD's than the 178 daily maximum. Thus, the range of VPD's measured in these experiments (up to 5 or $6 \mathrm{kPa}$; 179 Table 2), is representative of the extremes of the hot, arid climate of California. 


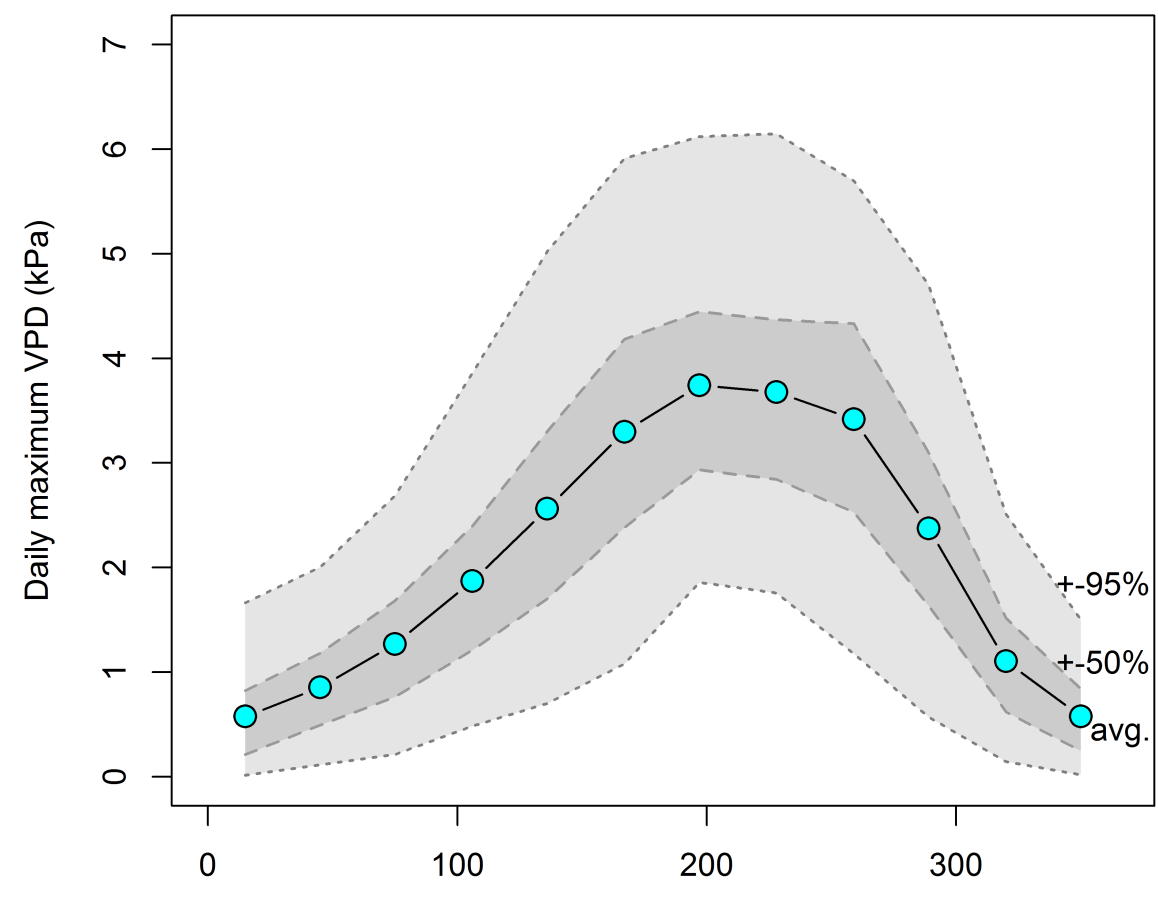

Days of the year

181 Fig. 1. Variation in the daily maximum VPD for Davis CA for the period 1983 to 2015. Values 182 are the average daily maximum VPD for each month, or the interval containing 50 or $95 \%$ of 183 daily maximum VPD values.

\section{COLOR SHOULD NOT BE USED IN PRINT}

\subsection{Gas exchange measurements}

A LICOR6400 with $2 \mathrm{~cm}^{2}$ fluorometer attachment, or the standard LED-lit, $6 \mathrm{~cm}^{2}$ chamber (LI-COR, Lincoln, NE) were used to measure stomatal conductance $\left(g_{\mathrm{H} 2 \mathrm{O}}\right)$.

189 Measurements were made by measuring all genotypes in a block, including both irrigation 190 treatments, and then advancing to another block. The order of block measurement was 191 randomized each day. Measurements were on sunny days starting between 8:30 - 11:00AM and 
192 ending between 4:10 - 6:00PM allowing a wide range of VPD to be measured in one day. In 193 Davis, VPD typically increases due to increasing air temperature, not vapor pressure, during the 194 day until late afternoon; thus measurements represent stomatal response to increasing VPD. 195 Time-of-day effects could not be distinguished from VPD effects as the two co-vary strongly. A 196 trifoliolate leaf was selected for measurement based upon being in the sun and fully expanded. 197 Chamber conditions were: saturating PPFD, ranging between experiments from 1600 to 2000 $198 \mu \mathrm{mol} \mathrm{m} \mathrm{m}^{-2}$, and set at a particular level for the entirety of an experiment; flow, 250 to $400 \mu \mathrm{mol}$ $199 \mathrm{~s}^{-1}$ for the fluorometer chamber and 500 to $700 \mu \mathrm{mol} \mathrm{s}^{-1}$ for the large chamber and chamber $\mathrm{CO}_{2}$, $200400 \mu \mathrm{mol} \mathrm{mol}{ }^{-1}$.

201 Evaporative conditions inside a gas exchange chamber are not possible to match with the 202 ambient environment, and no effort was made to do so here. Specifically, in order to measure 203 stomatal conductance the chamber removes the boundary layer from the measured leaf 204 (McDermitt, 1990). This means that even if air humidity, air and leaf temperature were equalized 205 before and after putting the leaf in the chamber, then the evaporative conditions would still be 206 different. Instead, the chamber was allowed to equilibrate for between 120 and 180 seconds, and 207 stomatal conductance measured, avoiding time for the stomata to respond to the new 208 environment. Thus, the measurements were intended to represent the stomatal conductance to the 209 ambient conditions, not to those inside the chamber. An exception was that when leaf 210 temperatures in the chamber exceeded $\sim 38^{\circ} \mathrm{C}$, rapid stomatal closure was observed during the 211 equilibration period. To avoid such hydropassive or damage responses, chamber wall (block) 212 temperature was generally set at $35^{\circ} \mathrm{C}$ when needed to avoid extreme leaf temperatures, but was 213 set at $39^{\circ} \mathrm{C}$ when needed in the 2014 field experiment. In effect, the chamber air temperature 
214 varied with ambient conditions until it reached a threshold after which it was controlled by the 215 cap on block temperature.

216 Simultaneous measurements of air temperature and relative humidity were measured 217 either using a HTM2500LF sensor (Measurement Specialties Inc., Toulouse, France) attached to 218 the exterior of the LICOR6400 and covered by a unaspirated radiation shield (2013 and 2014 219 field experiments), or a Campbell Scientific (Logan, Utah) weather station with a unaspirated 220 radiation- shielded HMP60 sensor for the other experiments. The weather stations were situated 221 within the experimental fields (less than 50m from all measurements), and the air temperature 222 sensor positioned at $2 \mathrm{~m}$ height above ground.

227 model (multiple regression) for each experiment separately. The basic model used was $g_{\mathrm{H} 2 \mathrm{O}}$ as 228 response variable, VPD as covariate and genotype as factor (Fig. 2). The interaction between 229 VPD and genotype was tested to determine if there were genotype differences in slope of the $230 g_{\mathrm{H} 2 \mathrm{O}}$ to VPD relationship, as is standard for testing the assumptions of ANCOVA (step A and B, 231 Fig. 2). Thus, if the interaction term was not significant (step C, Fig. 2), then it was removed and 232 slopes considered equal for all genotypes (Engqvist, 2005). The effect of the Day of 233 measurement and Block effects were included in the linear model as additional factors. 
Differences in slopes between/within experiments would lead to difficulty in interpreting results by outliers and single points.

extrapolated Y-intercepts, thus a standard value, the fitted $g_{\mathrm{H} 2 \mathrm{O}}$ value at low VPD (i.e. VPD $=2$ $\mathrm{kPa}$ ) was used when comparing species between experiments. Due to a large variation in scale, the natural logarithmic transformation was used to compare $g_{\mathrm{H} 2 \mathrm{O}}$ values between experiments.

Given the variability in the data, an important question is whether linear regression can detect stomatal closure. Specifically, what is the probability of avoiding a type II error, i.e., finding a regression slope of zero when a slope really exists? Firstly, a standard value of closure was used based upon the observed closure for soybean measured in Davis by the same authors (Medina and Gilbert, 2016), i.e., closure was considerable if there was a 40\% decrease between 1 and 4kPa VPD. Type II errors were assessed by resampling (with replacement) the observed pairs of $g_{\mathrm{H} 2 \mathrm{O}}$ and VPD data within a genotype within an experiment (R Core Team, 2016). Fitting lines to each of these bootstraps generated a confidence interval of the $g_{\mathrm{H} 2 \mathrm{O}}$ to VPD relationship for each genotype, and a probability that the data could represent a standard $40 \%$ stomatal closure could be approximated. Bootstrapping was chosen to avoid undue bias of the 


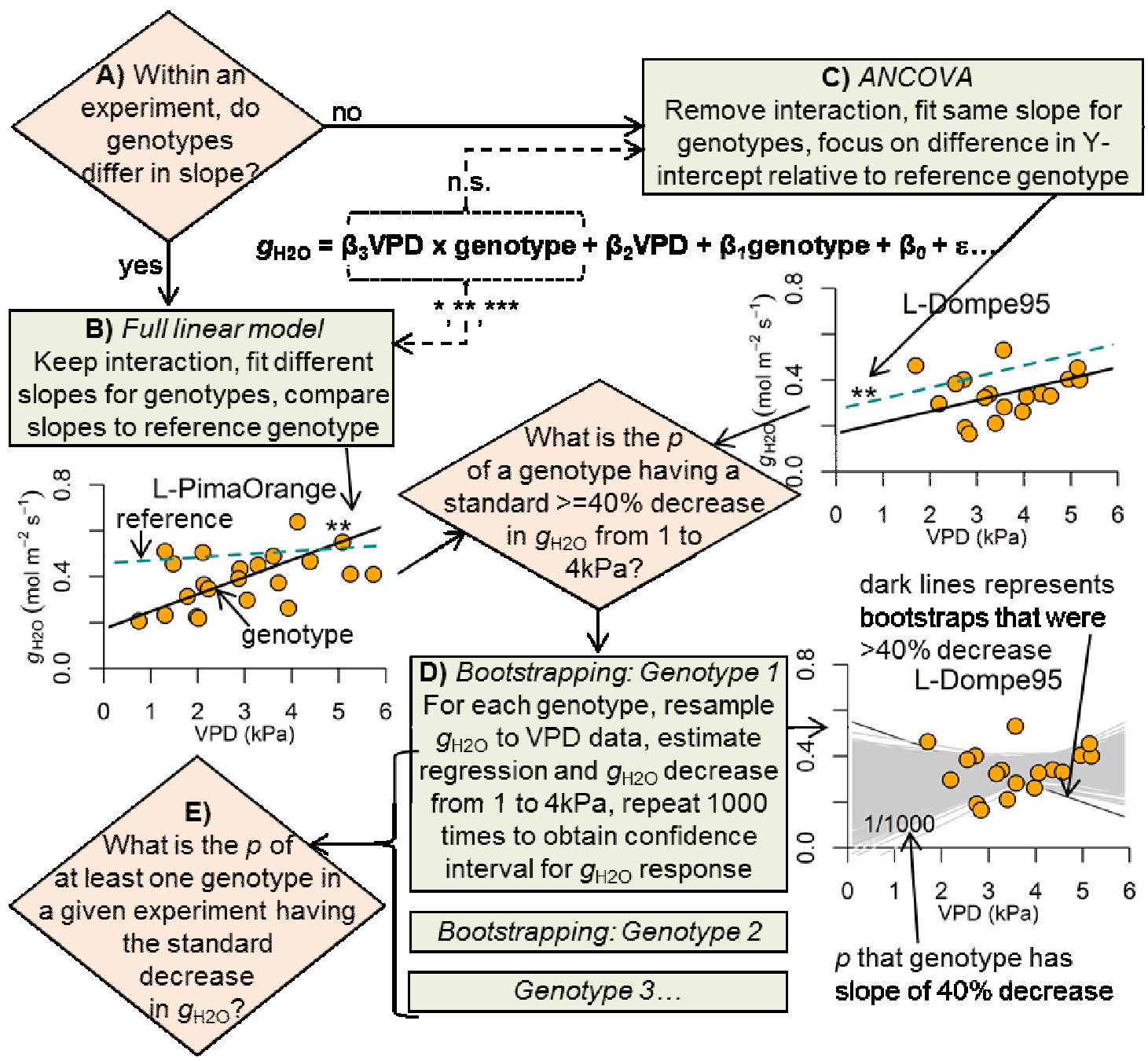

251 Fig. 2. Statistical procedure used to evaluate whether the relationship of $g_{\mathrm{H} 2 \mathrm{O}}$ to VPD of 252 genotypes varied within an experiment (step A, B or C), evaluation of the probability that a 253 genotype had at least a $40 \%$ decrease in $g_{\mathrm{H} 2 \mathrm{O}}$ over the VPD range 1 to $4 \mathrm{kPa}$ (step D), similar to 254 that observed in Medina and Gilbert (2016), and the evaluation of experiment-wise probability of 255 a standard decrease in at least one genotype (step E). 
A second analysis directly tested the power of detecting stomatal closure. Three datasets 259 were available that contained a large number of observations of the $g_{\mathrm{H} 2 \mathrm{O}}$ versus VPD 260 relationship: the original dataset of Medina and Gilbert (2016) for two very similar genotypes of 261 soybean showing a $40 \%$ decrease in $g_{\mathrm{H} 2 \mathrm{O}}$; and in experiment $\mathrm{B}$ and $\mathrm{C}$, described above, 262 measurements of genotypes were paired with measurements of a common bean (BAT477) grown 263 as a control in the same pot. A random resampling (with replacement) of pairs of $g_{\mathrm{H} 2 \mathrm{O}}$ and VPD 264 was performed 10000 times for each dataset using PopTools (Hood, 2010). The number of 265 samples resampled from each dataset was varied from ten samples to the total number in the 266 dataset. For each sample, linear regression was used to estimate the percentage change in $g_{\mathrm{H} 2 \mathrm{O}}$ 267 with a shift from 1 to $4 \mathrm{kPa}$ VPD. Then for each sample size, for each dataset, the $95 \%$ 268 confidence interval was found of the percentage change. From this the sample size was found 269 that had sufficient power to reliably distinguish the standard closure from those of BAT477 in 270 Experiment $\mathrm{B}$ or $\mathrm{C}$. A parametric equivalent to this analysis was also performed using the $p w r$ 271 package of $\mathrm{R}$ (Champely et al., 2016), asking: What is the probability (power) of avoiding a type

272 II error? Thus, for the correlation coefficient of the Medina and Gilbert (2016) dataset and an 273 alpha of 0.05 , the power could be found for varying sample sizes.

\section{3. Results}

The responses of $g_{\mathrm{H} 2 \mathrm{O}}$ to VPD were comparable between the years of measurements 279 measured in the field on diverse common beans (Fig. 3), with the two years having the same 
280 slope (VPD x Year: $F_{1,234}=0.513, p=0.474$; with analysis limited to genotypes common to both 281 years), but was $0.130 \mathrm{~mol} \mathrm{~m}^{-2} \mathrm{~s}^{-1}$ higher in Y-intercept in 2014 (Year: $F_{1,234}=18.1, p<0.001$ ). 282 All genotypes had the same statistical slope of $g_{\mathrm{H} 2 \mathrm{O}}$ response to VPD (slope $=-0.052 \mathrm{~mol} \mathrm{~m}^{-2} \mathrm{~s}^{-1}$ $283 \mathrm{kPa}{ }^{-1}$; Genotype x VPD: $F_{13,334}=1.05, p=0.404$; VPD: $\left.F_{1,347}=51.9, p<0.001\right)$. These data 284 represent a $14 \%$ decrease in $g_{\mathrm{H} 2 \mathrm{O}}$ between VPD's of 1 and $4 \mathrm{kPa}$ for the average genotype. Year 285 and Day of measurement had large effects (Year: $F_{1,347}=15.3, p<0.001$; Day: $F_{3,347}=8.27, p<$ 286 0.001). Y-intercept differed between genotypes (range $0.654 \mathrm{~mol} \mathrm{~m}^{-2} \mathrm{~s}^{-1}$; Genotype: $F_{13,347}=$ $28718.9, p<0.001)$. Relative to Victor (C-Victor), the common bean used as a reference, the two 288 lima beans in 2013 had a lower Y-intercept as did a number of common beans (Pinto San Rafael, 289 SER118, and ICA Bunsi; $p$-values given in figures) while two common beans had higher $g_{\mathrm{H} 2 \mathrm{O}}$ 290 (Matterhorn and Flor de Mayo Eugenia). The terminal drought led to considerable stomatal 291 closure in the 2014 experiment, indicating that had there been considerable closure at high VPD 292 in the well-watered treatment, it would have been observed. 


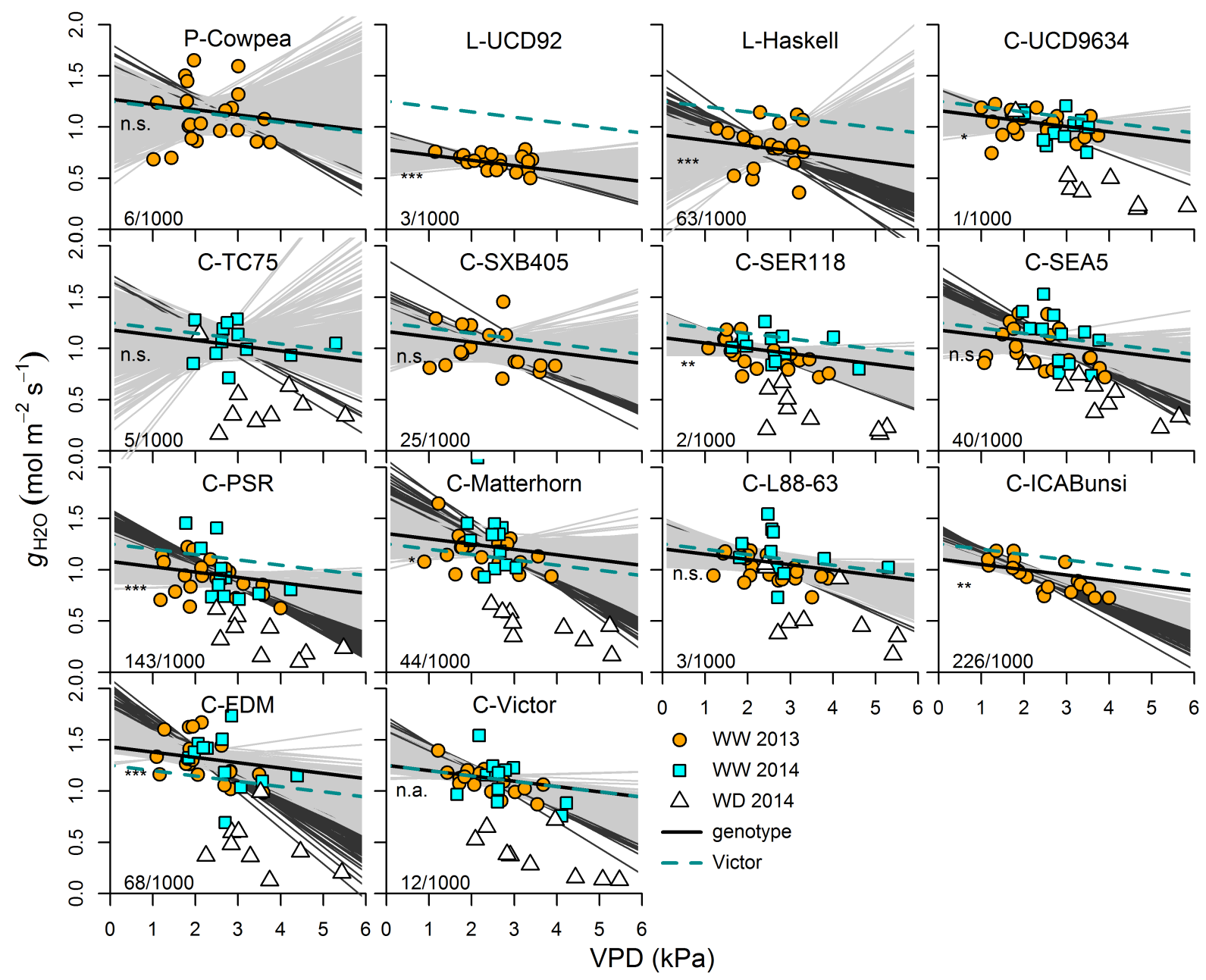

294 Fig. 3. Stomatal conductance $\left(g_{\mathrm{H} 2 \mathrm{O}}\right)$ to vapor pressure deficit (VPD) responses for the 2013 and 2952014 field trial (Experiment A). The dashed line represents the reference genotype Victor, and 296 solid line the linear model fit for the genotype of interest. Significance values (*** etc) represent 297 the difference between the Y-intercept of the genotype of interest and the reference genotype. 298 Light and dark lines represent 1000 bootstrap fits to a genotype, with dark lines and values (e.g. $2996 / 1000$ ) representing the fits that had closure of at least $40 \%$ between 1 and $4 \mathrm{kPa}$, similar to 300 closure observed previously in soybean (Medina and Gilbert, 2016). C, common bean; L, lima 301 bean; P, cowpea. 


\subsection{Experiment B (Outdoor pots 2014)}

The same core selection of eight common beans as in Experiment A were measured in

307 relationship (Genotype $\mathrm{x}$ VPD: $F_{7,196}=0.512, p=0.825$ ) and the general slope was positive

308 (slope $=0.095 \mathrm{~mol} \mathrm{~m} \mathrm{~s}^{-1} \mathrm{kPa}^{-1} ; \mathrm{VPD}: F_{1,203}=11.0, p=0.001$ ). Day of measurement had large

309 effect (Day: $\left.F_{6,203}=10.5, p<0.001\right)$ while Block had little effect (Block: $F_{3,203}=1.68, p=$

310 0.173). Flor de Mayo Eugenia (C-FDM) had a higher $g_{\mathrm{H} 2 \mathrm{O}}$, consistent with Experiment A

311 (Genotype: $F_{7,203}=5.97, p<0.001$ ). Extreme stomatal closure was present on the two days of

312 greatest water deficit for the water deficit (WD) pot measured immediately after the well-

313 watered pot (WW).

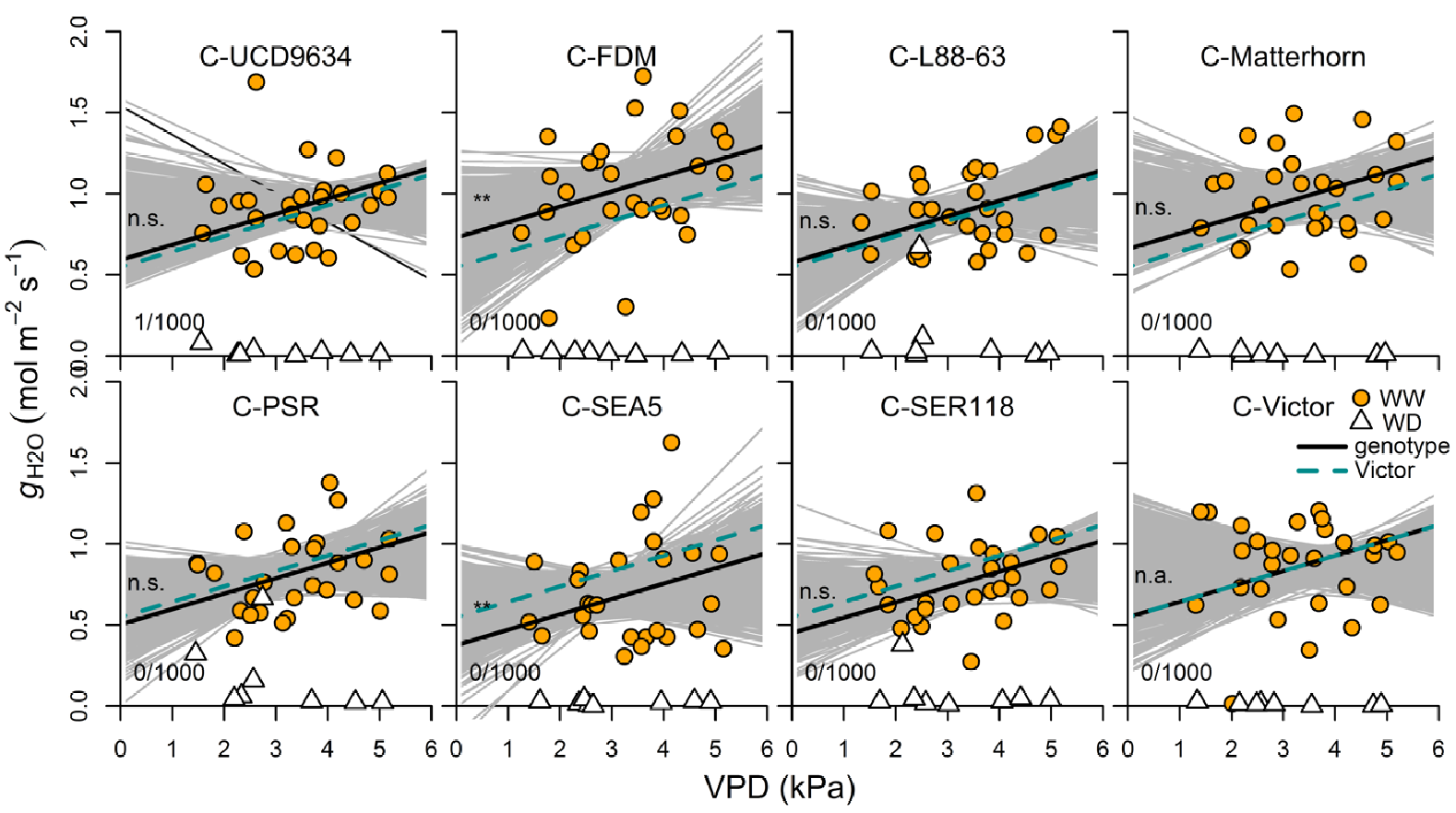


315 Fig. 4. Stomatal conductance $\left(g_{\mathrm{H} 2 \mathrm{O}}\right)$ to vapor pressure deficit (VPD) responses for the 2014 316 outdoor pot experiment (Experiment B) with similar common bean genotypes to Experiment A.

317 The dashed line represents the reference genotype Victor, and solid line the linear model fit for 318 the genotype of interest. Significance values represent the difference between the Y-intercept of 319 the genotype of interest and the reference genotype. Light and dark lines represent 1000 320 bootstrap fits to a genotype, with dark lines and values (e.g., 1/1000) representing the fits that 321 had closure of at least $40 \%$ between 1 and $4 \mathrm{kPa}$, similar to closure observed previously in 322 soybean (Medina and Gilbert, 2016). C, common bean.

\section{COLOR SHOULD NOT BE USED IN PRINT}

\subsection{Experiment $C$ (Outdoor pots 2014)}

The absolute values of $g_{\mathrm{H} 2 \mathrm{O}}$ measured in the Experiment $\mathrm{C}$ and subsequent field experiment (D) were about half of the values in experiment A and B (Fig. 3 and 4 compared to 5 and 6). It is unclear what the reason for this difference was, as Experiments A, B and D were measured with the same LICOR6400, while Experiment C used another. The first LICOR6400 was calibrated prior to experiment $\mathrm{A}$, and after use in D was checked and found to be accurate,

331 thus calibration does not explain the differences between Experiment A, B and the lower values in D. Measurements of BAT477 in Experiment B and C demonstrated that the two LICOR6400's appeared to be calibrated differently (for water or temperature, but not $\mathrm{CO}_{2}$ ). Regardless, all data within an experiment were measured using the same gas exchange system, and were internally measuring closure. 
There were no significant differences in the slope of the $g_{\mathrm{H} 2 \mathrm{O}}$ to VPD relationship in

338

Experiment C (Fig. 5; Genotype x VPD: $F_{8,143}=0.948, p=0.479$ ) and the general slope was small and positive (slope $=0.078 \mathrm{~mol} \mathrm{~m}^{-2} \mathrm{~s}^{-1} \mathrm{kPa}^{-1}$; VPD: $F_{1,151}=6.76, p=0.0102$ ). Day of measurement had large effect (Day: $F_{4,151}=6.19, p<0.001$ ) while Block had a smaller effect (Block: $F_{3,151}=3.76, p=0.012$ ). Stomatal conductance varied between genotypes, with two lima bean genotypes, Dompe 95 and G26451 lower than the common bean California Early Light Red Kidney used as a reference (Genotype: $F_{8,158}=3.40, p=0.0012$ ). Extreme stomatal closure was present in the WD treatment, similar to Experiment B.

The pot experiment data for B and C were noisy, and it could be argued that visually the points appear random, despite strong statistical support. However, for every measurement of a genotype in a pot, a matching measurement was made on BAT477, a common bean, planted in all pots as a within-pot control. There were no significant effects of companion genotype on BAT477's $g_{\mathrm{H} 2 \mathrm{O}}$ to VPD relationship (data not shown; Experiment B - Companion genotype $\mathrm{x}$ VPD: $F_{7,196}=1.01, p=0.425 ;$ VPD: $F_{2,196}=0.794, p=0.374$; Companion genotype: $F_{7,196}=$ 1.18, $p=0.314$; Day: $F_{4,196}=10.5, p<0.001$; Block: $F_{3,196}=1.68, p=0.173$; Experiment $\mathrm{C}$ Companion genotype x VPD: $F_{8,142}=0.559, p=0.81$; VPD: $F_{1,142}=0.176, p=0.68$; Companion genotype: $F_{8,142}=1.90, p=0.065$; Day: $F_{4,142}=7.15, p<0.001$; Block: $\left.F_{3,142}=2.89, p=0.037\right)$. These are a strong indication that the results of Experiments B and C were statistically robust. Outlying values of $g_{\mathrm{H} 2 \mathrm{O}}$ for a genotype (e.g., lower than $0.2 \mathrm{~mol} \mathrm{~m}^{-2} \mathrm{~s}^{-1}$ at low VPD), in general, had matching low values for BAT477, indicating a potspecific reason for the outliers. 


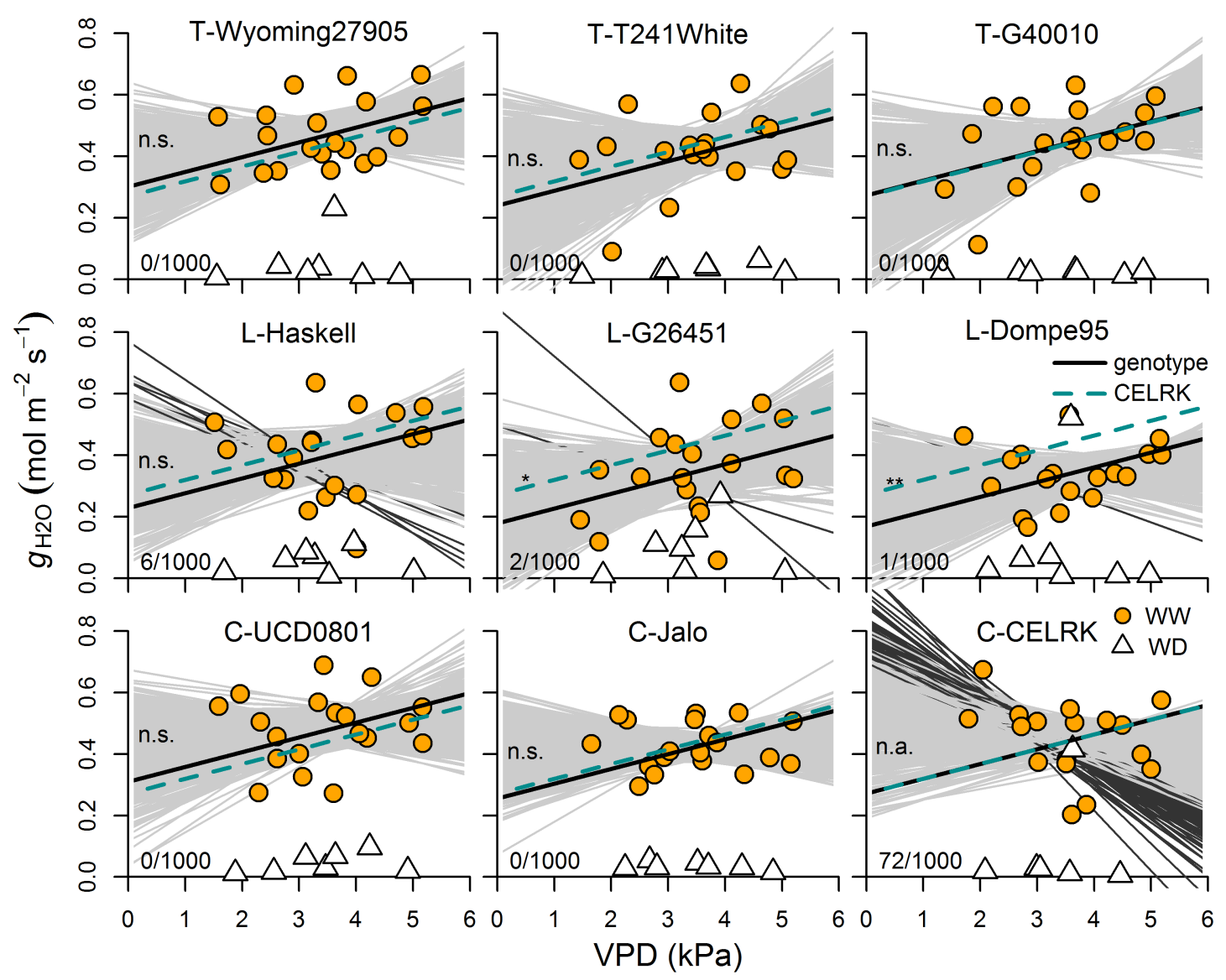

Fig. 5. Stomatal conductance $\left(g_{\mathrm{H} 2 \mathrm{O}}\right)$ to vapor pressure deficit (VPD) responses for the 2014 outdoor pot experiment comparing species (Experiment C). The dashed line represents the reference genotype California Early Light Red Kidney bean, and solid line the linear model fit

361 for the genotype of interest. Significance values represent the difference between the Y-intercept 362 of the genotype of interest and the reference genotype. Light and dark lines represent 1000 363 bootstrap fits to a genotype, with dark lines and values (e.g. 6/1000) representing the fits that had 364 closure of at least $40 \%$ between 1 and $4 \mathrm{kPa}$, similar to closure observed previously in soybean 365 (Medina and Gilbert, 2016). C, common bean; L, lima bean; T, tepary. 


\subsection{Experiment D (Field 2015)}

There were differences in slope between genotypes for the $g_{\mathrm{H} 2 \mathrm{O}}$ to VPD relationship in 371 experiment D (Fig. 6; Genotype x VPD: $F_{12,280}=1.93, p=0.031$ ), and no significant main slope

372 effect (VPD: $F_{1,280}=0.402, p=0.527$ ). Genotypes had variation in $g_{\mathrm{H} 2 \mathrm{O}}$ for a given VPD 373 (Genotype: $F_{12,280}=7.21, p<0.001$ ). The slope of Pima Orange was highest, and different from 374 Victor, the reference. Although slopes varied, all five teparies and two lima beans had lower $g_{\mathrm{H} 2 \mathrm{O}}$ 375 for most of the VPD range relative to common bean, Victor. In all field trials, Victor had one of 376 the highest $g_{\mathrm{H} 2 \mathrm{O}}$ 's similar to Flor de Mayo Eugenia, which was consistently the highest. Terminal 377 drought led to considerable stomatal closure in tepary and common bean genotypes, but not lima 378 beans, which did not show other symptoms of stress either (stem water potentials were similar 379 between treatments for lima bean accession's). 


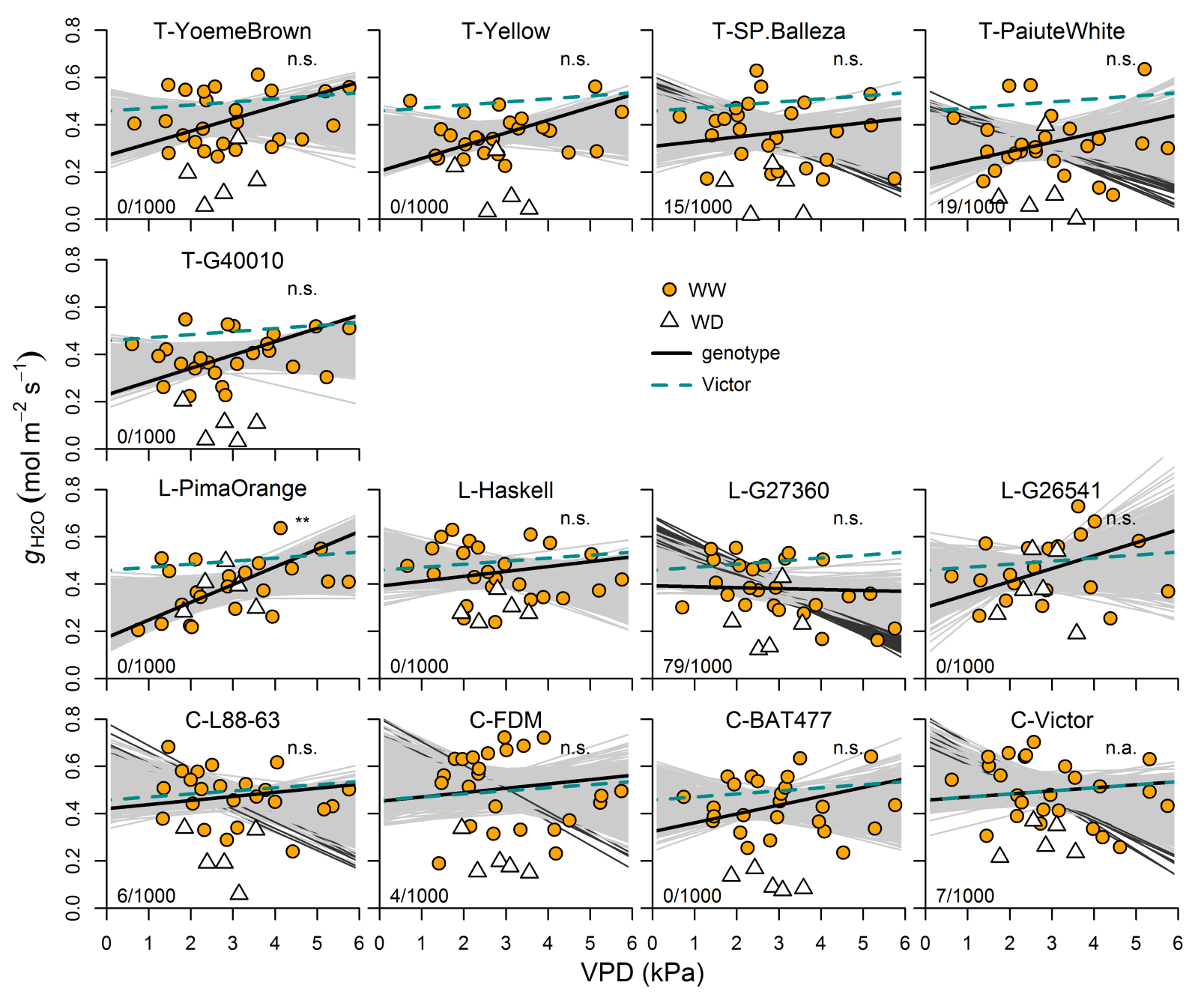

380

381 Fig. 6. Stomatal conductance $\left(g_{\mathrm{H} 2 \mathrm{O}}\right)$ to vapor pressure deficit (VPD) responses for the 2015 field 382 experiment comparing species (Experiment D). The dashed line represents the reference 383 genotype Victor, and solid line the linear model fit for the genotype of interest. Significance 384 values represent the difference between the slope of the genotype of interest and the reference 385 genotype. Light and dark lines represent 1000 bootstrap fits to a genotype, with dark lines and 386 values (e.g. 6/1000) representing the fits that had closure of at least $40 \%$ between 1 and $4 \mathrm{kPa}$, 387 similar to closure observed previously in soybean (Medina and Gilbert, 2016). C, common bean; 388 L, lima bean; T, tepary. 


\subsection{Evaluation of statistical power}

Four lines of evidence indicate that there was limited stomatal closure present in the many genotypes sampled. Firstly, soil water deficit treatments led to large decreases in stomatal conductance, indicating that if closure had occurred then the equipment and experimental design were capable of measuring the closure. Secondly, if $\sim 25$ random pairs of $g_{\mathrm{H} 2 \mathrm{O}}$ and VPD were drawn from the large dataset of Medina and Gilbert (2016), representing the standard case of $40 \%$ closure in soybean, then this sample size would be sufficient to detect a statistical difference to a slope of zero. The control genotype, BAT477, in Experiment B or C showed a significant difference to the standard soybean data with a sample size of 25, confirming this analysis (Fig. 7A). Thirdly, a similar parametric analysis also indicated that a sample size of $\sim 25$ is needed to have a power of 0.95 , or $95 \%$ probability of avoiding type II errors (Fig. 7B). Sample sizes, per genotype, were: Experiment A between 12 and 33 (average 26, majority > 30); B between 27 and 28; C between 18 and 20; D between 20 and 25 (average 24, majority 25). Thus, most analyses had approximately sufficient samples to result in a power to avoid type II errors of 0.9 or higher.

Finally, bootstraps of the slope of the relationship of $g_{\mathrm{H} 2 \mathrm{O}}$ to VPD for each genotype 405 indicated that Experiment $\mathrm{A}$ had $p=0.496$ that at least one genotype had a slope of greater than $40 \%$ closure, with four of fourteen genotypes being not significantly different to a slope of $40 \%$,

407 but in all cases the average slope was shallower than $40 \%$. Experiment B was not consistent with 408 closure $(p=0.001$, that at least one genotype had $40 \%$ closure $)$. Experiment $\mathrm{C}$ had $p=0.081$ 409 probability that at least one genotype had closure, with only one genotype (California Early Light Red Kidney bean) showing any probability of closure $(p=0.072)$. Experiment $\mathrm{D}$ had a $p=$ 
4110.129 that at least one genotype had closure, with only one genotype with a non-significant slope 412 to a $40 \%$ closure $(p=0.068)$.

413 A broader question is why there is high variability in stomatal conductance for a given 414 VPD and within a genotype? Day of measurement effects were considerable and further 415 experimentation is necessary to evaluate the reasons for this. A partial explanation for variability 416 in $g_{\mathrm{H} 2 \mathrm{O}}$ is that at high values the equation used has a small denominator, leading to noise in 417 primary measurements propagating large noise in $g_{\mathrm{H} 2 \mathrm{O}}$. That is, the primary measurement, total 418 conductance has a denominator of leaf internal water vapor mole fraction minus ambient water 419 vapor mole fraction (Anonymous, 2011). This difference is minimized as stomatal conductance 420 increases, and as internal water vapor is calculated from leaf temperature, small noise in leaf 421 temperature leads to increasing variability in conductance. 


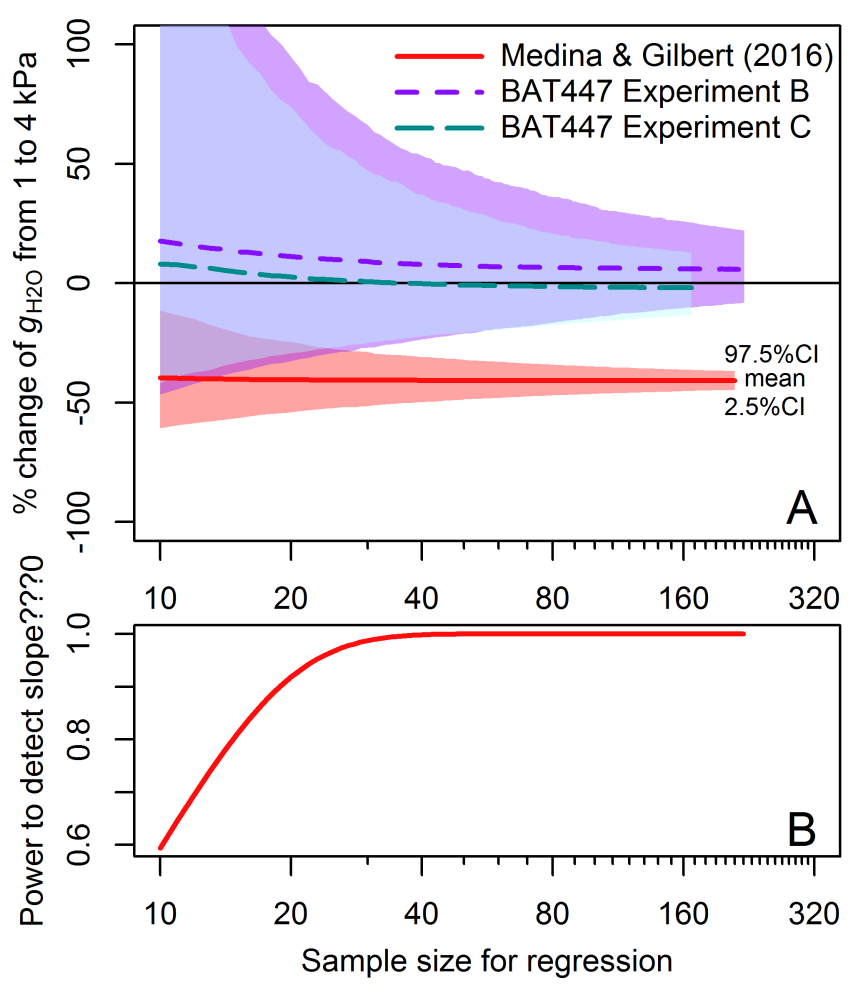

424 Fig. 7. Confidence intervals $(95 \%)$ of the percentage change in stomatal conductance between 1 425 and $4 \mathrm{kPa}$ VPD, as estimated by linear fits to resamples of large datasets varying the size of the 426 resample (panel A) and power to detect the standard 40\% stomatal closure with varying sample 427 sizes for the data of Medina and Gilbert (2016) (panel B). Three available large datasets 428 representing specific genotypes were compared, each with large sample sizes and each simulated 429 for sample sizes varying from ten to the total dataset size. See Materials and methods for details 430 of analysis. 
A consistent pattern across Experiments A, C and D was the lower $g_{\mathrm{H} 2 \mathrm{O}}$ of lima bean relative to common bean (Fig. 8; Species: $F_{1,21}=222.7, p<0.001$; genotype $g_{\mathrm{H} 2 \mathrm{O}}$ predicted for 2

$436 \mathrm{kPa}$ was used as replicates, and tepary beans were removed as teparies were not represented in 437 the first experiment). The $g_{\mathrm{H} 2 \mathrm{O}}$ of tepary bean genotypes was lower than lima bean in the field, 438 but higher in pots (Species x Experiment: $F_{2,16}=7.43, p=0.005$; comparing just the experiments 439 with teparies: pot experiment $\mathrm{C}$ and field experiment $\mathrm{D})$.

\section{Experiment}

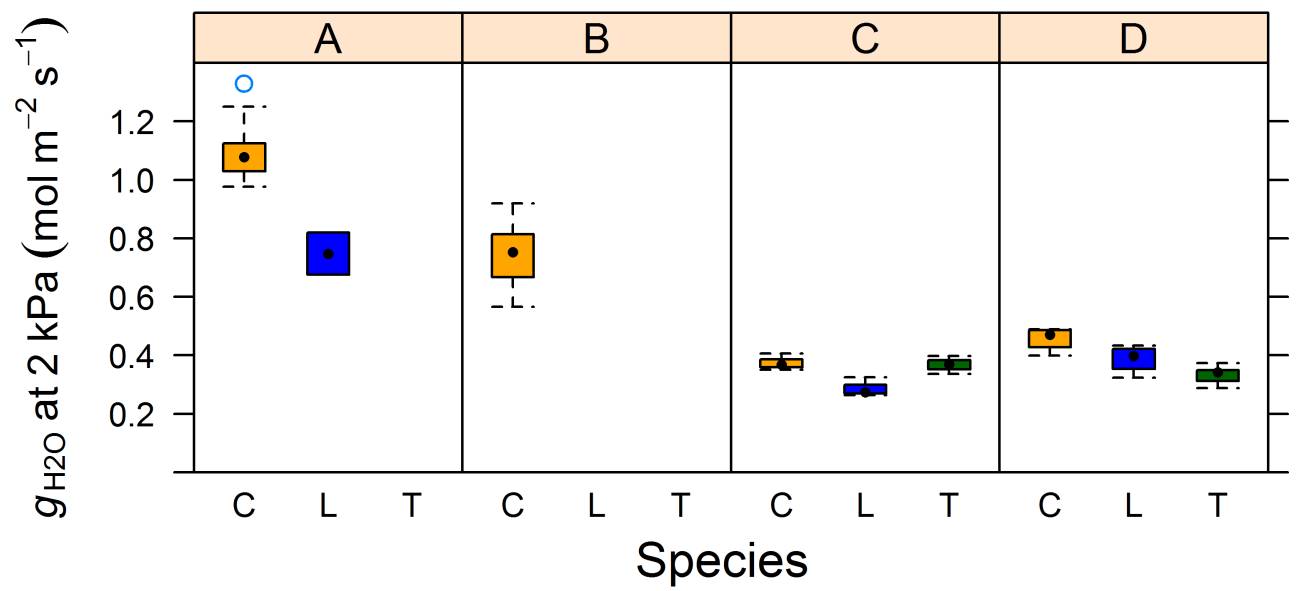

442 Fig. 8. Species differences in stomatal conductance $\left(g_{\mathrm{H} 2 \mathrm{O}}\right.$ predicted for $\left.2 \mathrm{kPa}\right)$ across the four 443 experiments (A to D). For each box shown, three or more genotypes were sampled for each 444 species in all experiments except lima bean in $\mathrm{A}$, in which $\mathrm{n}=2$ genotypes). $\mathrm{C}$, common bean; $\mathrm{L}$, 445 lima bean; T, tepary. Box and whisker plots represent the median, 25 and 75 percentiles and 446 range of the data. 


\section{Discussion}

\subsection{Limited VPD responses}

An evaluation of the genetic variation in stomatal conductance $\left(g_{\mathrm{H} 2 \mathrm{O}}\right)$ response to vapor 454 pressure deficit (VPD) was performed for three species of Phaseolus including 28 genotypes of 455 diverse origins. However, relative to past literature for other crops, limited variation was found 456 in stomatal closure under high VPD.

Across four experiments there was genotypic variation in the slope of the $g_{\mathrm{H} 2 \mathrm{O}}$ to VPD response in one experiment (Fig. 6). Treating each genotype individually, there was some limited 459 support for the possibility of a $40 \%$ change in $g_{\mathrm{H} 2 \mathrm{O}}$ from 1 to $4 \mathrm{kPa} \mathrm{VPD}$, with one genotype 460 having $p=0.226$. Thus, within an experiment, genotypes largely shared a similar sensitivity to 461 VPD, varying between a 14\% decrease to 50\% increase between low and high VPD (1 to $4 \mathrm{kPa}$ ). 462 In comparison, soybean genotypes that have a limited transpiration response to VPD display a $46340 \%$ decrease in stomatal conductance across the same range of VPDs for Davis, CA (Medina 464 and Gilbert, 2016). In North Carolina, the same soybean genotypes showed a $\sim 50$ to $90 \%$ 465 decrease for a less extreme range of VPD's (Gilbert et al., 2011). Past work on common bean is 466 difficult to compare to these data. Common bean, possibly including the genotype Victor, 467 demonstrated stomatal closure at VPD's of 20 to $50 \mathrm{mbar} / \mathrm{bar}$ ( 2 to $5 \mathrm{kPa}$ ) (Comstock and 468 Ehleringer, 1993). However, the experiments were conducted in greenhouses with limited 469 exposure to high VPD during growth. To be clear, those authors did excellent hydraulic work, 470 but it is difficult to extrapolate from those data whether similar stomatal closure would occur in 
471 the field. In the current experiment, the leaves were measured without time for stomata to

472 equilibrate to the gas exchange chamber and thus more closely represent the field responses to 473 VPD.

The unexpected result reported here warrants the question of whether there was a 475 "machinery problem" preventing measurement of low $g_{\mathrm{H} 2 \mathrm{O}}-$ but in all four experiments parallel 476 measurements on drought exposed plants showed moderate to severe stomatal closure, strongly 477 demonstrating that if stomatal closure at high VPD had occurred, then it would have been 478 measured. 480 species lose the limited transpiration behavior when exposed to high temperatures (Sermons et 481 al., 2012; Yang et al., 2012; Seversike et al., 2013; Riar et al., 2015; Shekoofa et al., 2015). In 482 those studies a threshold of about $30^{\circ} \mathrm{C}$ resulted in less limitation on transpiration possibly due to 483 an inducible mechanism. If such a mechanism was present in common bean, then the hot 484 conditions of the current experiments may result in loss of the limited-transpiration trait. Possibly 485 Phaseolus beans in lower temperature environments may then display stomatal closure at 486 moderate VPD's. An alternative explanation is that the lack of stomata sensitivity of cultivated 487 Phaseolus species represents one end of a continuum of response types (Mencuccini and 488 Comstock, 1999), similar to the extreme position of cotton (Lu and Zeiger, 1994). Unlike many 489 natural plants (Sperry et al., 2002), Phaseolus must have considerable investment in hydraulic 490 structure to allow them to avoid critical transpiration rates whilst maintaining high stomatal 491 conductance at high VPD. 
The VPD range measured here was large in comparison to other experiments but

493 applicable to the California Central Valley environment generally. Most agricultural

494 environments are likely to have extreme VPD's less than $5 \mathrm{kPa}$ (e.g., for an air temperature of $49540^{\circ} \mathrm{C}$, relative humidity must be below $33 \%$ to result in a more severe VPD, or at $45^{\circ} \mathrm{C}$, RH must 496 be $<50 \%$; or at $35^{\circ} \mathrm{C}$, RH must be $<12 \%$ ). Thus, these three species of Phaseolus showed an 497 excellent ability to maintain stomatal apertures under a very broad range of evaporative 498 demands, and in general, are not expected to have stomatal closure under hot, well-watered field 499 conditions.

\subsection{Species differences}

Tepary bean agriculture is considered as extremely drought tolerant (Nabhan, 1990).

503 However, the drought tolerance may apply to the type of agriculture (floodplain, short season),

504 rather than to plant hydraulic responses. Tepary did not appear to conserve water at high VPD

505 through stomatal closure in any of the experiments here, and the maximal stomatal conductance 506 appeared high and comparable to the other species. Thus, tepary's drought tolerance may be 507 more closely related to a fast growth habit, early maturity and deep rooting than water 508 conservation. These characteristics allow better water status at maturation and enhanced 509 photosynthate partitioning to seeds (Rao et al., 2013). Diverse common beans showed 510 considerable variation in maximum stomatal conductance and thus it seems that there is genetic 511 variation that can be used for breeding. In particular, Flor de Mayo Eugenia consistently had the 512 highest $g_{\mathrm{H} 2 \mathrm{O}}$ 's in all experiments where it was included. Maximum stomatal conductance is 
513 likely related to stomatal density, patterning and stomata size (Franks and Beerling, 2009),

514 particularly in species such as these that show little hydraulic limitation to transpiration.

515 Lima beans consistently had lower stomatal conductance than common beans in all three 516 experiments where lima's were included. Such a constitutive low conductance may lead to water

517 conservation relative to common bean under all conditions. However, the absolute values of $g_{\mathrm{H} 2 \mathrm{O}}$

518 for lima are still high relative to many crops or natural plants (Wright et al., 2004). Thus, it is 519 unclear how large a change in canopy transpiration would occur as a result of lower $g_{\mathrm{H} 2 \mathrm{O}}$ in lima 520 bean relative to common bean.

524 Phaseolus species having constraints on transpiration under high evaporative demands, under 525 well-watered conditions. No genotype showed large decreases (50-90\%) in stomatal 526 conductance, despite considerable evaporative demand. A few genotypes were not 527 distinguishable from a 40\% decrease, but generally showed less sensitive responses. Thus, future 528 searches for sensitive stomatal responses in Phaseolus beans will have to include wild relatives. 529 Alternatively, the stomatal sensitivity to VPD behavior may be under inducible genetic control, 530 and may not be expressed under in hot environments such as California's. If so, then future work 531 may need to either genetically alter the temperature threshold for the inducible behavior, or find 532 dry, mild temperature environments where the stomatal closure behavior is expressed and would 533 have a water conservation advantage. 


\section{Acknowledgements}

Thanks for the excellent comments of two reviewers. Thanks to field help from G.

537 Théroux-Rancourt, J. Orozco, M.I. Hernandez, R. Carlesso Aita, S. Dohle, H. Sharifi, E.

538 Konzen, L. Gamiño, and A. Palkovic. Germplasm Repositories that provided seeds are thanked

539 including International Center for Tropical Agriculture (CIAT, Cali, Colombia), United States

540 Department of Agriculture (USDA Western Plant Introduction Station, Pullman, WA, USA), and

541 Michigan State University (East Lansing, MI, USA), and Instituto Nacional de Investigaciones

542 Pecuarias, Agricolas y Forestales (INIFAP, Celaya, Guanajuato, Mexico).

543 Funding: V.M. was supported by Henry Jastro Awards, J.B. by CONACYT-UCMEXUS,

544 M.E.G was supported by the USDA NIFA, Hatch project \#1001480, and P.G. by USDA NIFA

545 AFRI 2016-67013-24460.

546

547 
$548 \quad$ References

549 Anonymous, 2011. Using the LI-6400/LI-6400XT Portable Photosynthesis System V6. LI-COR 550 Biosciences, Lincoln, NE.

551 Belko, N., Zaman-Allah, M., Diop, N., Cisse, N., Zombre, G., Ehlers, J., Vadez, V., 2012.

552 Restriction of transpiration rate under high vapour pressure deficit and non-limiting water

553 conditions is important for terminal drought tolerance in cowpea. Plant Biology 15, 304-316.

554 Champely, S., Ekstrom, C., Dalgaard, P., Gill, J., Weibelzahl, S., De Rosario, H., 2016. The 'pwr' 555 package: basic functions for power analysis. R Foundation for Statistical Computing, Vienna, 556 Austria.

557 CIMIS, 2015. California Irrigation Management Information System. California Department of 558 Water Resources, Sacramento, CA. 
559 Comstock, J., Ehleringer, J., 1993. Stomatal response to humidity in common bean (Phaseolus

560 vulgaris): implications for maximum transpiration rate, water-use efficiency and productivity.

561 Functional Plant Biology 20, 669-691.

562 Debouck, D.G., 1999. Diversity in Phaseolus species in relation to the common bean. Common 563 bean improvement in the twenty-first century. Springer, pp. 25-52.

564 Delgado Salinas, A., Gama López, S., 2015. Diversidad y distribución de los frijoles silvestres en 565 México. . Universidad Nacional Autónoma de México Revista Digital Universitaria 16.

566 Devi, M.J., Sinclair, T.R., Vadez, V., 2010. Genotypic variation in peanut for transpiration 567 response to vapor pressure deficit. Crop Science 50, 191-196.

568 Engqvist, L., 2005. The mistreatment of covariate interaction terms in linear model analyses of 569 behavioural and evolutionary ecology studies. Animal Behaviour 70, 967-971.

570 Franks, P.J., Beerling, D.J., 2009. Maximum leaf conductance driven by CO2 effects on stomatal 571 size and density over geologic time. Proceedings of the National Academy of Sciences 106, $572 \quad 10343-10347$.

573 Freeman, G.F., Station, U.o.A.A.E., 1912. Southwestern Beans and Teparies. University of 574 Arizona.

575 Freytag, G., Debouck, D.G., 2002. Taxonomy, distribution, and ecology of the genus Phaseolus 576 (Leguminosae-Papilionodeae) in North America, Mexico and Central America. . SIDA, 577 Botanical Miscellany.

578 Gepts, P., 2001. Phaseolus vulgaris (Beans). In Encyclopedia of Genetics.Academic Press, $579 \quad 1444-1445$. 
580 Gholipoor, M., Choudhary, S., Sinclair, T.R., Messina, C.D., Cooper, M., 2013. Transpiration 581 Response of Maize Hybrids to Atmospheric Vapour Pressure Deficit. J. Agron. Crop Sci. 199, $582 \quad 155-160$.

583 Gholipoor, M., Prasad, P.V.V., Mutava, R.N., Sinclair, T.R., 2010. Genetic variability of 584 transpiration response to vapor pressure deficit among sorghum genotypes. Field Crops Res. 119, $585 \quad 85-90$.

586 Gilbert, M., Holbrook, N.M., Zwieniecki, M., Sadok, W., Sinclair, T.R., 2011. Field 587 confirmation of genetic variation in soybean transpiration response to vapor pressure deficit and 588 photosynthetic compensation for this effect. Field Crop. Res. 124, 85-92.

589 Hood, G., 2010. PopTools version 3.2.5.

590 King, C.A., Purcell, L.C., Brye, K.R., 2009. Differential wilting among soybean genotypes in 591 response to water deficit. Crop Sci. 49, 290-298.

592 Lu, Z., Zeiger, E., 1994. Selection for higher yields and heat resistance in Pima cotton has caused 593 genetically determined changes in stomatal conductances. Physiologia plantarum 92, 273-278.

594 Maquet, A., Vekemans, X., Baudoin, J.P., 1999. Phylogenetic study on wild allies of Lima 595 bean,Phaseolus lunatus (Fabaceae), and implications on its origin. Plant Systematics and 596 Evolution 218, 43-54.

597 McDermitt, D., 1990. Sources of error in the estimation of stomatal conductance and 598 transpiration from porometer data. Hortsci. 25, 1538-1548.

599 Medina, V., Gilbert, M.E., 2016. Physiological trade-offs of stomatal closure under high 600 evaporative gradients in field grown soybean. Functional Plant Biology, - 
601 Mencuccini, M., Comstock, J., 1999. Variability in hydraulic architecture and gas exchange of 602 common bean (Phaseolus vulgaris) cultivars under well-watered conditions: interactions with 603 leaf size. Functional Plant Biology 26, 115-124.

604 Nabhan, G., 1990. Gathering the Desert. University of Arizona Press, Tucson.

605 Polania, J.A., Poschenrieder, C., Beebe, S., Rao, I.M., 2016. Effective Use of Water and 606 Increased Dry Matter Partitioned to Grain Contribute to Yield of Common Bean Improved for 607 Drought Resistance. Frontiers in plant science 7.

608 R Core Team, 2016. R: A language and environment for statistical computing. R Foundation for 609 Statistical Computing, Vienna, Austria.

610 Rainey, K.M., Griffiths, P.D., 2005. Evaluation of Phaseolus acutifolius A. Gray plant 611 introductions under high temperatures in a controlled environment. Genet Resour Crop Evol 52, $612 \quad 117-120$.

613 Rao, I., Beebe, S., Polania, J., Ricaurte, J., Cajiao, C., Garcia, R., Rivera, M., 2013. Can tepary 614 bean be a model for improvement of drought resistance in common bean? African Crop Science 615 Journal 21.

616 Riar, M.K., Sinclair, T.R., Prasad, P.V., 2015. Persistence of limited-transpiration-rate trait in 617 sorghum at high temperature. Environmental and Experimental Botany 115, 58-62.

618 Sadok, W., Sinclair, T.R., 2009. Genetic variability of transpiration response to vapor pressure 619 deficit among soybean cultivars. Crop Science 49, 955-960. 
620 Schoppach, R., Sadok, W., 2012. Differential sensitivities of transpiration to evaporative demand 621 and soil water deficit among wheat elite cultivars indicate different strategies for drought 622 tolerance. Envir. Exp. Bot. 84, 1-10.

623 Sermons, S.M., Seversike, T.M., Sinclair, T.R., Fiscus, E.L., Rufty, T.W., 2012. Temperature 624 influences the ability of tall fescue to control transpiration in response to atmospheric vapour 625 pressure deficit. Functional Plant Biology 39, 979-986.

626 Seversike, T.M., Sermons, S.M., Sinclair, T.R., Carter, T.E., Rufty, T.W., 2013. Temperature 627 interactions with transpiration response to vapor pressure deficit among cultivated and wild 628 soybean genotypes. Physiologia plantarum 148, 62-73.

629 Shekoofa, A., Rosas-Anderson, P., Sinclair, T.R., Balota, M., Isleib, T.G., 2015. Measurement of 630 Limited-Transpiration Trait under High Vapor Pressure Deficit for Peanut in Chambers and in 631 Field. Agronomy Journal 107, 1019-1024.

632 Sinclair, T., Devi, J., Carter, T., Jr., 2016. Limited-Transpiration Trait for Increased Yield for 633 Water-Limited Soybean: From Model to Phenotype to Genotype to Cultivars. In: Yin, X., Struik, 634 P.C. (Eds.), Crop Systems Biology. Springer International Publishing, pp. 129-146.

635 Sinclair, T.R., Messina, C.D., Beatty, A., Samples, M., 2010. Assessment across the United 636 States of the benefits of altered soybean drought traits. Agron. J. 102, 475-482.

637 Singh, S.P., 2001. Broadening the genetic base of common bean cultivars. Crop Science 41, $638 \quad 1659-1675$.

639 Sperry, J.S., Hacke, U., Oren, R., Comstock, J., 2002. Water deficits and hydraulic limits to leaf 640 water supply. Plant, Cell \& Environment 25, 251-263. 
641 Wright, I.J., Reich, P.B., Westoby, M., Ackerly, D.D., Baruch, Z., Bongers, F., Cavender-Bares, 642 J., Chapin, T., Cornelissen, J.H.C., Diemer, M., Flexas, J., Garnier, E., Groom, P.K., Gulias, J., 643 Hikosaka, K., Lamont, B.B., Lee, T., Lee, W., Lusk, C., Midgley, J.J., Navas, M.L., Niinemets, 644 U., Oleksyn, J., Osada, N., Poorter, H., Poot, P., Prior, L., Pyankov, V.I., Roumet, C., Thomas, 645 S.C., Tjoelker, M.G., Veneklaas, E.J., Villar, R., 2004. The worldwide leaf economics spectrum. $646 \quad$ Nature 428, 821-827.

647 Yang, Z., Sinclair, T.R., Zhu, M., Messina, C.D., Cooper, M., Hammer, G.L., 2012. Temperature 648 effect on transpiration response of maize plants to vapour pressure deficit. Envir. Exp. Bot. 78, $649 \quad 157-162$.

650 Zaman-Allah, M., Jenkinson, D.M., Vadez, V., 2011. Chickpea genotypes contrasting for seed 651 yield under terminal drought stress in the field differ for traits related to the control of water use. 652 Functional Plant Biology 38, 270-281. 